\title{
Effect of copper sulphate on hydrogen peroxide bleaching with hydrolysis on p/c fabric mechanical properties
}

\begin{abstract}
Surface modification of polyester and Polyester/Cotton material is not a new concept to a processing man. Alkaline oxidation of $\mathrm{P} / \mathrm{C}$ blends with copper sulphate, hydrogen peroxide and base hydrolysis has shown some interesting trends. The present work includes the investigation of effect of padding copper sulphate (3 levels) and bleaching with hydrogen peroxide followed by base hydrolysis ( $2 \%$ concentration) at 1:5 and 1:10 MLRs with treatment temperature selected at 110 and 120 degrees centigrade on fabric mechanical properties like tensile strength, bending length, crease recovery and compressibility. In general it is observed that following copper sulphate treatment the weight increases, and decreases after bleaching. Due to the action of caustic, substrate suffers from loss of weight due to removal of chains from surface by $\mathrm{NaOH}$. With increase in bath ratio $(\mathrm{w} / \mathrm{v})$ and concentration of copper sulphate, an increase in weight after copper sulphate treatment is observed, followed by decrease in weight after bleaching and loss of weight following hydrolysis. The increase in weight with increase in copper sulphate concentration is mainly due to padding. The results clearly show a positive shift following alkaline oxidation and hydrolysis from gray level. Higher bath ratios with higher hydrolysis temperature have registered a positive shift by about $30 \%$.Decrease in bending length following bleaching and base hydrolysis has indicated the softness of the substrate. At higher bath ratio and hydrolysis temperature, as copper sulphate concentration increases, nearly $20 \%$ positive shift is observed in stiffness values. Due to alkaline oxidation and base hydrolysis with higher copper sulphate concentration at higher bath ratio and temperature, nearly $20 \%$ negative shift increase recovery values have proved that fabric has become softer following finishing. An excellent compression behavior is observed in bleached, hydrolysed samples. With increase in copper sulphate concentration the compressibility has registered an increasing trend with hydrolysed samples.
\end{abstract}

Volume 2 Issue 3 - 2017

\author{
Hayavadana J, Samatha K \\ Textile Technology, Osmania University, India
}

\begin{abstract}
Correspondence: Hayavadana J, Textile Technology, University College of Technology, Osmania University, Hyderabad, India, Email haya_guru@rediffmail.com
\end{abstract}

Received: February II, 2017 | Published: July 20, 2017

\section{Introduction}

The popularity of $\mathrm{P} / \mathrm{C}$ blends at various levels in different fields is the main reason behind the surface modification of $\mathrm{P} / \mathrm{C}$ blends. In the present day $\mathrm{P} / \mathrm{C}$ blends are mainly used for dress materials. To modify the surface, oxidation deweighting process experiments were carried out on $\mathrm{P} / \mathrm{C}$ blended fabric. The cotton fiber is accessible to damage and easy to degrade in certain conditions after being oxidized. The metal ions in the fabric may accelerate the decomposition of hydrogen peroxide and damage the cotton fiber. Among metal ions, copper ranks first in catalyzing such decomposition. On the other hand research studies have confirmed that iron ions may form brown rusty spots on the fabric. If the padded fabric is oxidized by hydrogen peroxide before finishing, the copper ions would drift away from the fabric to the hydrogen peroxide solution, causing effective decomposition of hydrogen peroxide which does not contact the fabric. In oxidation deweighting, the hydrogen peroxide should decompose on the fabric as much as possible and oxidize the cotton fiber. Therefore the fabric is padded with copper sulphate and dried before oxidizing.

Gao Ming \& Dong Ying ${ }^{2}$ has studied alkaline oxidation of $\mathrm{P} / \mathrm{C}$ blended poplin fabric. In their study the relation between deweighting ratio with copper sulphate and hydrogen peroxide is reported. Process parameters like bath ratio, treatment times and concentration of $\mathrm{NaOH}$ on deweighting ratio are also reported. Although a considerable work has been reported on the effect of alkaline oxidation on deweighting ratio of $\mathrm{P} / \mathrm{C}$ blends, work on the effect of alkaline oxidation followed by base hydrolysis on fabric mechanical properties like tensile strength, bending length etc. is scanty in literature. Hence the thrust of the present investigation is to investigate the effect of alkaline oxidation followed by base hydrolysis for a suiting fabric on mechanical properties.

\section{Materials and methods}

\section{Materials}

The geometrical parameters of $67 / 33 \mathrm{P} / \mathrm{C}$ suiting fabric are as follows Ends/inch=68, picks/inch $=58$, count of warp and weft $=2 / 40 \mathrm{~s}$ $\mathrm{T} / \mathrm{C} \times 2 / 40 \mathrm{~s} T / \mathrm{C}$. The fabric was woven on ruti-c loom with 59.5 " reed space. The chemicals used were of laboratory grade and were not purified further.

\section{Methods}

Copper, sulphate padding with $10 \%, 20 \%$ and $30 \%$ was carried out in sealed beakers at room temperature using laboratory model HTHP beaker dyeing machine and dried in oven Zeronian. ${ }^{1}$ The pad-dried fabric samples were then bleached using hydrogen peroxide $(30 \%$ volume) at 60-80 degrees temperature. The procedure followed was recommended by Gao Ming \& Dong Ying. ${ }^{2}$ The bleached samples were then base hydrolysed using $2 \% \mathrm{NaOH}$ with $1: 5$ and $1: 10$ bath ratios (w/v) at 110 and 120 degrees for 30minutes. The purpose of using low liquor ration is on the concept of low liquor dyeing using HTHP machine. Table 1 shows the coding of fabric samples with 
roman II for bleached samples and roman I for hydrolysed samples, indicated throughout the experiment. The samples were washed with tap water to remove excess alkali, followed by neutralization with $0.5 \%$ acetic acid and finally washed in deionised water and dried in oven.

Table I Sample coding

\begin{tabular}{lllll}
\hline Code & $\begin{array}{l}\text { Copper } \\
\text { sulphate } \\
\text { concentration }\end{array}$ & $\begin{array}{l}\text { NAOH } \\
\text { concentration }\end{array}$ & $\begin{array}{l}\text { Liquor } \\
\text { ratio }\end{array}$ & $\begin{array}{l}\text { Temperature } \\
\text { (for } \\
\text { hydrolysis) }\end{array}$ \\
\hline $10 \mathrm{Cl}$ & $10 \%$ & $2 \%$ & $1: 05$ & I I0Degrees \\
$20 \mathrm{Cl}$ & $20 \%$ & $2 \%$ & $1: 05$ & I I0Degrees \\
$30 \mathrm{Cl}$ & $30 \%$ & $2 \%$ & $1: 05$ & I I0Degrees \\
$10 \mathrm{C} 2$ & $10 \%$ & $2 \%$ & $1: 05$ & I20Degrees \\
$20 \mathrm{C} 2$ & $20 \%$ & $2 \%$ & $1: 05$ & I20Degrees \\
$30 \mathrm{C} 2$ & $30 \%$ & $2 \%$ & $1: 05$ & I20Degrees \\
$10 \mathrm{C} 3$ & $10 \%$ & $2 \%$ & $1: 10$ & I I0Degrees \\
$20 \mathrm{C} 3$ & $20 \%$ & $2 \%$ & $1: 10$ & I I0Degrees \\
$30 \mathrm{C} 3$ & $30 \%$ & $2 \%$ & $1: 10$ & I I0Degrees \\
$10 \mathrm{C} 4$ & $10 \%$ & $2 \%$ & $1: 10$ & I20Degrees \\
$20 \mathrm{C} 4$ & $20 \%$ & $2 \%$ & $1: 10$ & I20Degrees \\
$30 \mathrm{C} 4$ & $30 \%$ & $2 \%$ & $1: 10$ & I20Degrees \\
\hline
\end{tabular}

\section{Conditioning and testing}

The finished samples were conditioned at standard atmospheric conditions $\mathrm{RH} 65+-2 \%$ and temperature $27+-2$ degrees as per IS
$6359-1971$

\section{Determination of geometrical properties}

Measurement of yarn linear density: Yarn count was determined as per IS1315 and an average of 10 measurements is reported.

\section{Measurement of yarn crimp}

The crimp of yarns unravelled from the test fabric was measured on Shirley crimp as per IS: 3442-1966. Measurements were taken in both warp and weft ways. The average was given in percentage using following formula.

$$
\% \text { Crimp }=\left(L_{2}-L_{1} / L_{1}\right) * 100
$$
yarn.

Where $\mathrm{L}_{1}=$ length of yarn in the fabric, $\mathrm{L}_{2}=$ stretched length of the

\section{Determination of fabric GSM}

GSM of the fabric samples was measured as per IS: 1964-1970. Fabric GSM was determined and the value reported is an average of measurements.

\section{Determination of fabric thickness (Compressibility)}

Fabric thickness was measured using Shirley thickness gauge as per the standard test method IS: 7702-1975. The result shown is an average of at least 10 random measurements. EMC of control and treated fabric samples are was determined using in Table 2:

$$
\operatorname{EMC}(\%)=\left(T_{o}-T_{m}\right) / T_{o} \times 100
$$

$\mathrm{T}_{\mathrm{o}}=$ Thickness at $0.5 \mathrm{gf} / \mathrm{cm}^{2} \mathrm{~T}_{\mathrm{m}}=$ Thickness at maximum load

\begin{tabular}{|c|c|c|c|c|c|c|}
\hline Sample & $50 \mathrm{~g}$ & $100 \mathrm{~g}$ & $150 \mathrm{~g}$ & $200 \mathrm{~g}$ & $250 \mathrm{~g}$ & $300 \mathrm{~g}$ \\
\hline Control & 4 & 6 & 8 & 11 & 12 & 14 \\
\hline $10 \mathrm{CI} I I$ & 4.3 & 6.8 & 10.34 & 11.2 & 12.06 & 12.93 \\
\hline $20 \mathrm{CI} I I$ & 3.27 & 4.9 & 8.19 & 9.8 & 10.65 & 11.47 \\
\hline $30 \mathrm{CI} I I$ & 1.6 & 5.6 & 6.45 & 8.8 & 9.6 & 11.29 \\
\hline $10 C 2$ II & 3.38 & 5.08 & 9.32 & 10.16 & 11.86 & $|2.7|$ \\
\hline $20 C 2$ II & 1.66 & 4.16 & 5.83 & 7.5 & 10.83 & 12.5 \\
\hline $30 C 2$ II & 1.61 & 4.83 & 7.25 & 8.87 & 11.29 & 12.9 \\
\hline $10 C 311$ & 3.33 & 5.83 & 7.5 & 9.16 & 10.83 & 12.5 \\
\hline $20 C 3$ II & 2.27 & 4.54 & 6.63 & 8.18 & 9.09 & 10.9 \\
\hline $30 C 3$ II & 3.5 & 5.26 & 7.01 & 8.77 & 10.52 & 11.4 \\
\hline I0C4 II & 4.16 & 5.8 & 8.3 & 10.83 & 15 & 16.66 \\
\hline $20 C 4$ II & 1.78 & 4.46 & 8.92 & 10.71 & 12.5 & 14.28 \\
\hline $30 C 4$ II & 3.33 & 5 & 6.66 & 8.33 & 9.16 & 12.5 \\
\hline Hydrolysed samples & 3 & 4 & 7 & 9 & 12 & 13 \\
\hline $\mathrm{IOCII}$ & 2.04 & 5.01 & 7.14 & 9.18 & 11.22 & 12.24 \\
\hline $20 \mathrm{CII}$ & 1.74 & 4.31 & 6.03 & 7.75 & 9.48 & 12.06 \\
\hline $30 \mathrm{CII}$ & 2.67 & 4.46 & 7.14 & 8.9 & 11.6 & 13.39 \\
\hline $10 C 21$ & 1.78 & 7.14 & 9.82 & 8.95 & 14.28 & 16.07 \\
\hline $20 C 2 \mathrm{I}$ & 1.75 & 3.5 & 6.14 & 7.89 & 10.52 & 12.28 \\
\hline $30 C 21$ & 2.7 & 4.6 & 6.48 & 9.25 & 11.11 & 12.96 \\
\hline
\end{tabular}

Table 2 Effect on Compressibility 
Table Continued...

$\begin{array}{lllllll}\text { Hydrolysed samples } & \mathbf{3} & \mathbf{4} & \mathbf{7} & \mathbf{9} & \mathbf{1 2} & \mathbf{1 3} \\ 10 \mathrm{C} 3 \mathrm{I} & \mathrm{I} .78 & 4.46 & 6.25 & 8.03 & 9.82 & 11.6 \\ 20 \mathrm{C} 3 \mathrm{I} & \mathrm{I} .85 & 3.7 & 6.48 & 8.33 & 11.11 & 12.03 \\ 30 \mathrm{C} 3 \mathrm{I} & 1.92 & 3.8 & 6.7 & 8.6 & 11.53 & 13.46 \\ 10 \mathrm{C} 4 \mathrm{I} & 1.96 & 3.9 & 5.8 & 7.8 & 9.8 & 10.78 \\ 20 \mathrm{C} 4 \mathrm{I} & 2.8 & 5.6 & 7.5 & 9.43 & 10.37 & 11.32\end{array}$

\section{Determination of fabric set}

Measurement of bending length: Shirley stiffness tester working on

Fabric set of the samples was determined as per IS: 1963-1969. This parameter defined the average distance between two consecutive threads in a fabric. Ends per inch and picks per inch are measured using Densimeter. The average of 10 observations selected randomly is reported as the final value which is later converted to threads per inch and was expressed in inches.

\section{Testing of mechanical properties}

Measurement of fabric tensile strength: Tensile strength of control and finished samples were measured as per IS1969-1968 using universal testing machine. Table 3 shows the tensile strength of control, bleached and hydrolysed samples.

Table 3 Effect on Tensile Strength

\begin{tabular}{|c|c|c|c|c|}
\hline \multirow[t]{2}{*}{ Sample } & \multicolumn{2}{|l|}{ Warp way } & \multicolumn{2}{|l|}{ Weft way } \\
\hline & Strength & \% Shift & Strength & \% Shift \\
\hline Control & 45.75 & - & 44 & - \\
\hline $\mathrm{IOCI} I I$ & 44 & 3.8 & 42 & 0.54 \\
\hline $20 \mathrm{CI} I I$ & 43 & 6.01 & 41 & 6.81 \\
\hline $30 \mathrm{CI} I I$ & 40 & 12.56 & 39 & 11.36 \\
\hline I0C2 II & 43 & 6.01 & 42 & 4.54 \\
\hline $20 C 2$ II & 37 & 19.12 & 37.2 & 15.45 \\
\hline $30 \mathrm{C} 2 \mathrm{II}$ & 44 & 3.8 & 43 & 2.27 \\
\hline $10 C 311$ & 43 & 6.01 & 40 & 9.09 \\
\hline $20 C 3$ II & 42 & 8.19 & 41 & 6.81 \\
\hline $30 \mathrm{C} 3 \mathrm{II}$ & 38 & 16.93 & 37 & 15.9 \\
\hline I0C4 II & 41 & 10.38 & 38 & 13.63 \\
\hline $20 C 4$ II & 38 & 16.93 & 36 & 18.18 \\
\hline $30 C 4$ II & 40 & 12.56 & 37 & \\
\hline \multicolumn{5}{|c|}{ Hydrolysed samples } \\
\hline $\mathrm{IOCI} I$ & 41 & 10.38 & 40 & 9.09 \\
\hline $20 \mathrm{CI} \mathrm{I}$ & 40 & 12.56 & 37 & 15.09 \\
\hline $30 \mathrm{Cl} \mathrm{I}$ & 36.4 & 20.43 & 40 & 9.09 \\
\hline $10 C 21$ & - & - & - & - \\
\hline $20 C 2$ I & - & - & - & - \\
\hline $30 C 2 I$ & 36 & 21.31 & 29.6 & 29.52 \\
\hline $10 C 31$ & 35.4 & 22.62 & 35 & 16.66 \\
\hline $20 C 31$ & 38 & 16.93 & 40 & 4.76 \\
\hline $30 C 31$ & - & - & - & - \\
\hline I0C4I & 38 & 16.93 & 36 & 14.28 \\
\hline $20 C 4 I$ & 36 & 21.31 & 34 & 19.04 \\
\hline
\end{tabular}
cantilever principle was used and the average of 10 replications is reported in Table 4 for control, beached and hydrolysed samples warp and weft way. The procedure followed is as per IS6490-1971.

Measurement of crease recovery: Shirley crease recovery tester was used to measure crease recovery angle of control bleached and finished angles as per IS4681-1968. The results reported as the average of 5 observations are shown in Table 5.

Table 4 Effect on bending length

\begin{tabular}{|c|c|c|c|c|}
\hline \multirow[t]{2}{*}{ Sample } & \multicolumn{2}{|l|}{ Warp way } & \multicolumn{2}{|l|}{ Weft way } \\
\hline & $\begin{array}{l}\text { Bending } \\
\text { length }(\mathrm{cm})\end{array}$ & $\%$ Shift & $\begin{array}{l}\text { Bending } \\
\text { length (cm) }\end{array}$ & $\%$ Shift \\
\hline Control & 1.7 & - & 1.6 & - \\
\hline $\mathrm{IOCI} \|$ & $1.5 \mathrm{I}$ & 11.17 & 1.38 & 13.75 \\
\hline $20 \mathrm{CI} I I$ & 1.61 & 5.29 & 1.55 & 3.12 \\
\hline $30 \mathrm{CI} \mathrm{II}$ & 1.66 & 2.35 & 1.36 & 15 \\
\hline $10 C 2$ II & 1.5 & 11.76 & 1.53 & 4.37 \\
\hline $20 C 2$ II & I.5। & 11.17 & 1.36 & 15 \\
\hline $30 C 2$ II & 1.61 & 5.29 & 1.36 & 15 \\
\hline $10 C 311$ & 1.55 & 8.82 & 1.46 & 8.75 \\
\hline $20 C 3$ II & 1.5 & 11.76 & 1.36 & 15 \\
\hline $30 C 3$ II & I.5। & 11.17 & $\mathrm{I} .4 \mathrm{I}$ & II.87 \\
\hline I0C4 II & 1.61 & 5.29 & $\mathrm{I} .48$ & 7.5 \\
\hline $20 C 4$ II & 1.43 & 15.88 & 1.36 & 15 \\
\hline $30 C 4$ II & 1.52 & 10.58 & 1.45 & 9.3 \\
\hline \multicolumn{5}{|c|}{ Hydrolysed samples } \\
\hline IOCI II & 1.3 & 23.52 & 1.26 & 21.25 \\
\hline $20 \mathrm{CI} I I$ & 1.45 & 14.7 & 1.46 & 8.75 \\
\hline $30 \mathrm{CI}$ II & 1.5 & 11.76 & 1.36 & 15 \\
\hline $10 C 2$ II & 1.35 & 20.58 & 1.28 & 20 \\
\hline $20 C 2$ II & 1.38 & 18.82 & 1.3 & 18.75 \\
\hline $30 C 2$ II & I.4I & 17.05 & 1.35 & 15.62 \\
\hline I0C3 II & 1.35 & 20.58 & 1.28 & 20 \\
\hline $20 C 3$ II & 1.43 & 15.88 & I.34 & 16.25 \\
\hline $30 C 3$ II & 1.46 & |4.II & 1.36 & 15 \\
\hline I0C4 II & 1.41 & 17.05 & 1.35 & 15.62 \\
\hline $20 C 4$ II & $1.4 \mathrm{I}$ & 17.05 & 1.3 & 18.75 \\
\hline
\end{tabular}

Citation: Hayavadana J, Samatha K. Effect of copper sulphate on hydrogen peroxide bleaching with hydrolysis on p/c fabric mechanical properties. J Textile Eng Fashion Technol. 2017;2(3):387-392. DOI: 10.15406/jteft.2017.02.00060 
Table 5 Effect on Crease Recovery

\begin{tabular}{|c|c|c|c|c|}
\hline \multirow[t]{2}{*}{ Sample } & \multicolumn{2}{|l|}{ Warp way } & \multicolumn{2}{|l|}{ Weft way } \\
\hline & $\begin{array}{l}\text { Crease } \\
\text { recovery } \\
\text { (Angle) }\end{array}$ & $\%$ Shift & $\begin{array}{l}\text { Crease } \\
\text { recovery } \\
\text { (Angle) }\end{array}$ & \% Shift \\
\hline Control & 99.5 & - & 115 & - \\
\hline $\mathrm{IOCI}||$ & 109.5 & 10.05 & 126.5 & 12 \\
\hline $20 \mathrm{CI} I I$ & 110 & 10.5 & 127 & 12.88 \\
\hline $30 \mathrm{CI} I I$ & 113.5 & 14.07 & 128.5 & 13.77 \\
\hline $10 C 2$ II & 115.25 & 15.82 & 129.5 & $|5.1|$ \\
\hline $20 C 2$ II & 117.5 & 18.09 & 131.75 & $|7.1|$ \\
\hline $30 C 2$ II & II4.5 & 15.07 & 125 & II.II \\
\hline I0C3 || & 112.5 & 13.06 & 124 & 10.22 \\
\hline $20 C 3$ II & 112 & 12.56 & 119.5 & 6.2 \\
\hline $30 C 3$ II & III & 11.55 & 122 & 8.4 \\
\hline I0C4 II & III.5 & 12.06 & 123 & 9.3 \\
\hline $20 C 4$ II & 119 & 19.59 & 126 & 12 \\
\hline $30 C 4$ II & 108 & 8.54 & 119 & 5.7 \\
\hline \multicolumn{5}{|c|}{ Hydrolysed samples } \\
\hline IOCI II & 111.5 & 12.06 & 128 & 13.77 \\
\hline $20 \mathrm{CI} I I$ & 113 & 13.56 & 129.5 & $|5.1|$ \\
\hline $30 \mathrm{CIII}$ & 118 & 18.59 & 132 & 17.33 \\
\hline I0C2 || & 116 & 16.58 & 129 & 14.66 \\
\hline $20 C 2$ II & 119.5 & 20.1 & $13 \mid .5$ & 16.88 \\
\hline $30 C 2$ II & 122.5 & 23.11 & 133.5 & 18.66 \\
\hline I0C3 II & 120.5 & 21.1 & $13 \mid .5$ & 16.88 \\
\hline $20 C 3$ II & 124 & 24.62 & 134 & 19.11 \\
\hline $30 C 3$ II & 125 & 25.62 & 135.5 & 20 \\
\hline |0C4 || & 121 & 21.6 & 132 & 17.33 \\
\hline $20 C 4$ II & 120 & 20.6 & $|3|$ & 16.44 \\
\hline
\end{tabular}

\section{Results and discussion}

\section{Effect on weight following each chemical treatment}

Table 6a shows the increase in weight after copper sulphate treatment and decrease in weight after bleaching and hydrolysis. It is clear that with the increase in copper sulphate concentration the increase in weight is due to padding. On the other hand the increase in weight loss after bleaching, as the copper sulphate concentration is increased, may be due to the removal impurities and the action of hydrogen peroxide on cotton. Similarly the weight loss after hydrolysis is due to the action of caustic on polyester. A height weight loss of $9 \%$ is observed with $30 \%$ copper sulphate concentration at 120 degrees temperature. Table $6 \mathrm{~b}$ high lights the $\%$ shift in the weight following each chemical treatment at 1:5 and 1:10 bath ratios. The $\%$ shift (positive and negative) in weight increases with increase in copper sulphate concentration. Trend is similar for bleached and hydrolysed samples. This may be due to the facts as explained above. The results are in concomitant with several researcher investigations.
Table 6a Weight loss of samples after each chemical treatment

\begin{tabular}{|c|c|c|c|}
\hline Sample & $\begin{array}{l}\% \text { Increase in } \\
\text { weight after } \\
\text { copper sulphate } \\
\text { treatment }\end{array}$ & $\begin{array}{l}\% \text { Decrease in } \\
\text { weight after } \\
\text { bleaching }\end{array}$ & $\begin{array}{l}\% \text { Decrease in } \\
\text { weight after } \\
\text { hydrolysis }\end{array}$ \\
\hline $\mathrm{IOCI} I$ & 5.4 & 5.4 & 6.2 \\
\hline $\mathrm{IOCI} I \mathrm{I}$ & 5.09 & 5.13 & - \\
\hline $20 \mathrm{Cl} \mathrm{I}$ & 8.4 & 6.34 & 6.3 \\
\hline $20 \mathrm{CI} I I$ & 6.2 & 5.01 & - \\
\hline $30 \mathrm{CI} \mathrm{I}$ & 8.6 & 6.66 & 5.52 \\
\hline $30 \mathrm{Cl} I I$ & 9.07 & 7.02 & - \\
\hline I0C2 I & 4.8 & 4.9 & 7.5 \\
\hline I0C2 II & 4.6 & 3.9 & - \\
\hline $20 C 2 \mathrm{I}$ & 5.7 & 4.8 & 7.1 \\
\hline $20 C 2$ II & 5.6 & 4.3 & - \\
\hline $30 C 2$ I & 5.8 & 3.8 & 8.4 \\
\hline $30 C 2$ II & 5.4 & 3.66 & - \\
\hline $10 C 31$ & 6.2 & 6.2 & 5.64 \\
\hline $10 C 3$ II & 4.08 & 4.3 & - \\
\hline $20 C 3 I$ & 9.7 & 8.3 & 5.22 \\
\hline $20 C 3$ II & 9.7 & 8.7 & - \\
\hline $30 C 31$ & 11.07 & 9.1 & 6.57 \\
\hline $30 C 3$ II & 12.97 & 10.95 & - \\
\hline I0C4 I & 15.3 & 13.28 & 9.05 \\
\hline I0C4 II & 7.1 & 5.8 & - \\
\hline $20 C 4$ I & 12.8 & 7.6 & 9.93 \\
\hline $20 C 4$ II & 6.7 & 6.5 & - \\
\hline $30 C 4 \mathrm{I}$ & 14.05 & 7.8 & 9.07 \\
\hline $30 C 4$ II & 14.36 & 7.5 & - \\
\hline
\end{tabular}

\section{Effect on tensile strength}

From the literature scan, it is observed that following base hydrolysis the fabric loses 5-10\% fabric strength. (Table 7a) (Table 7b) addresses the positive shift for bleached and hydrolysed samples at 1:5 and 1:10 bath ratios with 3 levels of copper sulphate concentration. It is clear from the table that \% shift increases in all cases with increase in copper sulphate concentration. This is due to loss in tensile strength following bleaching and hydrolysis. Reduction in tensile strength of bleached and hydrolysed samples may be due to gradual removal of molecular chains from the structure. The results are in agreement with findings by Zeronian \& Collin. ${ }^{1}$

\section{Effect on warp and weft way bending length}

The positive $\%$ shift in bending length values of warp weft at 1:5 and 1:10 bath ratios with increase in copper sulphate concentration for bleached and hydrolysed (110 and 120 degrees temperature) samples is reported in (Table 8a) (Table 8b). A general trend observed is that \% shift reduces with increase in copper sulphate concentration for warp but follows an irregular pattern for weft. The shift in bending length 
may be due to loss of weight following base hydrolysis. The fall in bending length values has clearly shown that fabric has imparted soft feeling.

\section{Effect on crease recovery}

Tables $9 a \& 9 b$ shows the average $\%$ shift (negative) increase recovery angle for bleached and hydrolysed samples in different conditions. With the increase in copper sulphate concentration and treatment temperature, the hydrolysed samples have shown larger Table 6b Effect of Chemical treatment crease recovery angles. This may be due to the fact that following weight loss, the fabric has become soft.

\section{Effect on compressibility}

Table 2 reports the EMC values for bleached and hydrolysed samples. It is observed that with increase in copper sulphate concentration, compressibility decreases for bleached samples. A reverse trend is observed in the case of hydrolysed samples.

\begin{tabular}{|c|c|c|c|c|}
\hline \multirow[t]{2}{*}{$\begin{array}{l}\text { Copper sulphate } \\
\text { concentration }\end{array}$} & \multirow[t]{2}{*}{$\begin{array}{l}\text { Average increase in weight after } \\
\text { copper sulphate treatment }\end{array}$} & \multirow[t]{2}{*}{$\begin{array}{l}\text { Average decrease in } \\
\text { weight after bleaching }\end{array}$} & \multicolumn{2}{|c|}{$\begin{array}{l}\text { Average decrease in weight after } \\
\text { hydrolysis at temperature }\end{array}$} \\
\hline & & & I I 0 degrees & I 20 degrees \\
\hline \multicolumn{5}{|l|}{ For $1: 5$ bath ratio: } \\
\hline $10 \%$ & 4.89 & 4.83 & 6.2 & 7.5 \\
\hline $20 \%$ & 6.47 & 5.11 & 5.52 & 8.4 \\
\hline $30 \%$ & 7.21 & 5.28 & 5.52 & 8.4 \\
\hline \multicolumn{5}{|c|}{ For I: 10 bath ratio: } \\
\hline $10 \%$ & 8.17 & 7.39 & 6.3 & 7.1 \\
\hline $20 \%$ & 9.725 & 7.75 & 5.22 & 9.93 \\
\hline $30 \%$ & 13.112 & 8.83 & 6.57 & 9.07 \\
\hline
\end{tabular}

Table 7a Average \% Shift for tensile strength of bleached samples

\begin{tabular}{lll}
\hline $\begin{array}{l}\text { Copper sulphate } \\
\text { concentration }\end{array}$ & Warp way shift & Weft way shift \\
\hline For I:5 bath ratio: & & \\
$10 \%$ & 4.905 & 4.54 \\
$20 \%$ & 12.56 & 11.17 \\
$30 \%$ & 8.17 & 6.81 \\
For I: 10 bath ratio: & & \\
$10 \%$ & 8.195 & 11.36 \\
$20 \%$ & 12.56 & 12.49 \\
$30 \%$ & 14.74 & 15.9 \\
\hline
\end{tabular}

Table 8a Average \% Shift for bending strength of bleached samples

\begin{tabular}{lll}
\hline $\begin{array}{l}\text { Copper sulphate } \\
\text { concentration }\end{array}$ & Warp way shift & Weft way shift \\
\hline For I:5 bath ratio: & 11.465 & 9.06 \\
$10 \%$ & 8.23 & 9.06 \\
$20 \%$ & 3.82 & 15 \\
$30 \%$ & & \\
For I: 10 bath ratio: & 7.05 & 8.125 \\
$10 \%$ & 13.82 & 15 \\
$20 \%$ & 10.87 & 10.58 \\
$30 \%$ & & \\
\hline
\end{tabular}

Table $\mathbf{7 b}$ Average \% shift for tensile strength of hydrolysed samples-Effect of Temperature

\begin{tabular}{lllll}
\hline $\begin{array}{l}\text { Copper } \\
\text { sulphate } \\
\text { concentration }\end{array}$ & \multicolumn{2}{c}{ Warp way shift } & \multicolumn{2}{l}{ Weft way shift } \\
\cline { 2 - 5 } & $\begin{array}{l}\text { II0 } \\
\text { degrees }\end{array}$ & $\begin{array}{l}\text { I20 } \\
\text { degrees }\end{array}$ & $\begin{array}{l}\text { I I0 } \\
\text { degrees }\end{array}$ & $\begin{array}{l}\text { I20 } \\
\text { degrees }\end{array}$ \\
\hline For I:5 bath ratio: & & & \\
$10 \%$ & 10.38 & - & 9.09 & - \\
$20 \%$ & 12.56 & - & 15.9 & - \\
$30 \%$ & 20.43 & 21.31 & 9.09 & 29.52 \\
For I: 10 bath ratio: & 22.62 & 16.93 & 16.66 & 14.28 \\
$10 \%$ & 16.93 & 21.31 & 15.9 & 19.04 \\
$20 \%$ & - & 21.31 & - & 30 \\
$30 \%$ & & & & \\
\hline
\end{tabular}

Table $\mathbf{8 b}$ Average \% shift for bending length of hydrolysed samples (Temperature)

\begin{tabular}{lllll}
\hline $\begin{array}{l}\text { Copper } \\
\text { sulphate } \\
\text { concentration }\end{array}$ & \multicolumn{2}{c}{ Warp way shift } & \multicolumn{2}{l}{ Weft way shift } \\
\cline { 2 - 5 } & $\begin{array}{l}\text { II0 } \\
\text { degrees }\end{array}$ & $\begin{array}{l}120 \\
\text { degrees }\end{array}$ & $\begin{array}{l}110 \\
\text { degrees }\end{array}$ & $\begin{array}{l}120 \\
\text { degrees }\end{array}$ \\
\hline \multicolumn{2}{l}{ For I:5 bath ratio: } & & & \\
$10 \%$ & 23.52 & 20.58 & 21.25 & 20 \\
$20 \%$ & 14.7 & 18.82 & 8.75 & 18.75 \\
$30 \%$ & 11.76 & 17.05 & 15 & 15.62 \\
For I: I0 bath ratio: & 20.58 & 17.05 & 20 & 15.62 \\
$10 \%$ & 15.88 & 17.05 & 16.25 & 18.75 \\
$20 \%$ & 14.11 & 11.76 & 15 & 21.87 \\
$30 \%$ & & & & \\
\hline
\end{tabular}

Citation: Hayavadana J, Samatha K. Effect of copper sulphate on hydrogen peroxide bleaching with hydrolysis on p/c fabric mechanical properties.J Textile Eng Fashion Technol. 2017;2(3):387-392. DOI: 10.15406/jteft.2017.02.00060 
Table 9a Average \% Shift for crease recovery of bleached samples

\begin{tabular}{lll}
\hline $\begin{array}{l}\text { Copper sulphate } \\
\text { concentration }\end{array}$ & Warp way shift & Weft way shift \\
\hline For I:5 bath ratio: & 12.935 & 13.55 \\
$10 \%$ & 14.29 & 14.99 \\
$20 \%$ & 14.57 & 12.44 \\
$30 \%$ & 12.56 & \\
For I: I0 bath ratio: & 16.075 & 9.77 \\
$10 \%$ & 10.045 & 9.11 \\
$20 \%$ & & 7.1 \\
$30 \%$ & & \\
\hline
\end{tabular}

Table $9 \mathbf{b}$ Average \% shift for crease recovery of hydrolysed samples (Temperature)

\begin{tabular}{lllll}
\hline $\begin{array}{l}\text { Copper sulphate } \\
\text { concentration }\end{array}$ & \multicolumn{2}{c}{ Warp way shift } & \multicolumn{2}{l}{ Weft way shift } \\
\cline { 2 - 5 } & $\begin{array}{l}\text { II } \\
\text { degrees }\end{array}$ & $\begin{array}{l}120 \\
\text { degrees }\end{array}$ & $\begin{array}{l}\text { I I0 } \\
\text { degrees }\end{array}$ & $\begin{array}{l}\text { I 20 } \\
\text { degrees }\end{array}$ \\
\hline For I:5 bath ratio: & & & & \\
$10 \%$ & 12.06 & 16.58 & 13.77 & 14.66 \\
$20 \%$ & 13.56 & 20.1 & 15.11 & 16.88 \\
$30 \%$ & 8.59 & 23.11 & 17.33 & 18.66 \\
For I:I0 bath ratio: & 21.1 & 21.6 & 16.88 & 17.33 \\
$10 \%$ & 24.62 & 20.6 & 19.11 & 16.44 \\
$20 \%$ & 25.62 & 25.62 & 20 & 19.11 \\
$30 \%$ & & & & \\
\hline
\end{tabular}

\section{Conclusion}

It is clear from the above discussions that $\mathrm{P} / \mathrm{C}$ blended fabrics can be imparted a soft silk like feeling following weight reduction by alkaline oxidation and base hydrolysis and the fabric will exhibit the following features.

a. The fabric is very sensitive to chemical processing like effect of Copper sulpahate, Bleaching and alkaline hydrolysis.

b. Improved Compressibility following finishing.

c. Higher crease recovery and lower bending length.

d. Acceptable strength loss.

\section{Acknowledgements}

None.

\section{Conflict of interest}

Author declares there is no conflict of interest in publishing the article.

\section{References}

1. Zeronian SH, Collins MJ. Surface modification of polyester by alkaline treatments. Textile Progress. 1989;20(2):1-26.

2. Gao Ming, Dong Ying. Treating fabric through alkaline oxidation for a silk-like effect. American Dyst Rep. 1996. p. 10-26. 